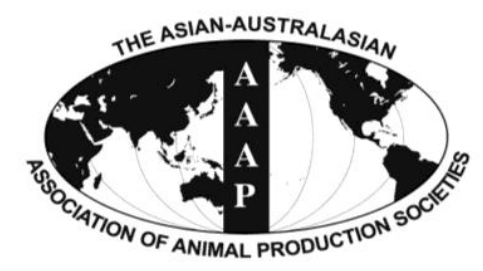

Asian Australas. J. Anim. Sci.

Vol. 26, No. 8 : 1172-1180 August 2013

http://dx.doi.org/10.5713/ajas.2013.13045

www.ajas.info

pISSN 101 1-2367 elSSN 1976-5517

\title{
Estimation of the Optimal Ratio of Standardized lleal Digestible Threonine to Lysine for Finishing Barrows Fed Low Crude Protein Diets
}

\author{
Chunyuan Xie, Shihai Zhang, Guijie Zhang, Fengrui Zhang, Licui Chu, and Shiyan Qiao* \\ State Key Laboratory of Animal Nutrition, College of Animal Science and Technology, \\ China Agricultural University, Beijing 100193, China
}

\begin{abstract}
Two experiments were conducted to determine the standardized ileal digestible (SID) lysine (Lys) requirement and the ideal SID threonine (Thr) to Lys ratio for finishing barrows. In Exp. 1, 120 barrows with an average body weight of $72.8 \pm 3.6 \mathrm{~kg}$ were allotted to one of six dietary treatments in a randomized complete block design conducted for $35 \mathrm{~d}$. Each diet was fed to five pens of pigs containing four barrows. A normal crude protein (CP) diet providing $15.3 \% \mathrm{CP}$ and $0.71 \%$ SID Lys and five low CP diets providing $12 \%$ CP with SID Lys concentrations of $0.51,0.61,0.71,0.81$ and $0.91 \%$ were formulated. Increasing the SID Lys content of the diet resulted in an increase in weight gain (linear effect $p=0.04$ and quadratic effect $p=0.08$ ) and an improvement in feed conversion ratio (FCR) (linear effect $\mathrm{p}=0.02$ and quadratic effect $\mathrm{p}=0.02$ ). For weight gain and FCR, the estimated SID Lys requirement of finishing barrows were 0.71 and $0.71 \%$ (linear broken-line analysis), 0.79 and $0.78 \%$ (quadratic analysis), respectively. Exp. 2 was a $26 \mathrm{~d}$ doseresponse study using SID Thr to Lys ratios of $0.56,0.61,0.67,0.72$ and 0.77 . A total of 138 barrows weighing $72.5 \pm 4.4 \mathrm{~kg}$ were randomly allotted to receive one of the five diets. All diets were formulated to contain $0.61 \%$ SID Lys (10.5\% CP), which is slightly lower than the pig's requirement. Weight gain was quadratically $(\mathrm{p}=0.03)$ affected by SID Thr to Lys ratio while FCR was linearly improved $(\mathrm{p}=0.02)$. The SID Thr to Lys ratios for maximal weight gain and minimal FCR and serum urea nitrogen (SUN) were 0.67, 0.71 and 0.64 using a linear broken-line model and $0.68,0.78$ and 0.70 using a quadratic model, respectively. Based on the estimates obtained from the broken-line and quadratic analysis, we concluded that the dietary SID Lys requirement for both maximum weight gain and minimum FCR was $0.75 \%$, and an optimum SID Thr to Lys ratio was 0.68 to maximize weight gain, 0.75 to optimize FCR and 0.67 to minimize SUN for finishing barrows. (Key Words: Threonine to Lysine Ratio, Standardized Ileal Digestible, Performance, Low Crude Protein, Pigs)
\end{abstract}

\section{INTRODUCTION}

Feed costs and nitrogen excretion may be reduced by replacing a portion of the dietary crude protein in swine diets with crystalline amino acid (AA; Deng et al., 2007a ; Chen et al., 2011). Pigs fed low crude protein (CP) diets (protein level reduced by three to four percentage units) supplemented with CAA have been shown to achieve the same performance as those fed normal (formulated to meet $\mathrm{CP}$ requirements) protein levels (Kerr et al., 2003; Deng et al., 2007b), while the amount of protein ingredients used and feed costs were both reduced.

Threonine (Thr) is the third limiting AA in corn based diets for pigs (Grosbach et al., 1985), and the first limiting AA for growing pigs fed low $\mathrm{CP}$ diets containing crystalline

\footnotetext{
* Corresponding Author: Shiyan Qiao. Tel: +86-10-62731456, Fax: +86-10-62733688, E-mail: qiaoshy@mafic.ac.cn Submitted Jan. 18, 2013; Accepted Apr. 5, 2013; Revised Apr. 12, 2013
}

lysine (Lys) when based on barley (Fuller et al., 1979) or grain sorghum (Hansen et al., 1993). Thr also plays very important role in animal mucosal mucins synthesis (Wang et al., 2007) and immune function ( $\mathrm{Li}$ et al., 1999; $\mathrm{Li}$ et al., 2007; Kim et al., 2007). Knowledge of the appropriate Thr levels to use in low CP corn soybean meal-based diets is extremely important to the swine industry because of the relatively low concentration of Thr in corn and the high cost of supplementation with crystalline Thr.

For finishing pigs, several studies have conducted to estimate the apparent ileal digestible Thr requirement (Saldana et al., 1994; Schutte et al., 1997) or standardized ileal digestible (SID) Thr requirement (Ettle et al., 2004). There were only two studies that reported the optimal SID Thr to Lys ratio for finishing pigs fed normal CP diets (Pedersen et al., 2003; Plitzner et al., 2007), in which the optimal SID Thr to Lys ratio was estimated to be 0.62 to 0.64 . However, less information was available on Thr to Lys 
ratio in finishing pigs fed reduced $\mathrm{CP}$ and AA supplemented diets.

To express the Thr requirement as a Thr to Lys ratio, Lys should be the second-limiting AA in the diet after Thr, and the requirements for the other essential AA were met or exceeded (Boisen, 2003). There are very few empirical studies have been conducted to determine the optimum SID Lys requirement. The SID Lys requirements of the selected studies in the National Research Council (NRC, 2012) were estimated from the diet composition at the defined requirement.

The objectives of the present experiments were to determine the optimal dietary SID Lys concentration and estimate the optimal SID Thr to Lys ratio for maximizing weight gain or minimizing FCR and serum urea nitrogen (SUN) of finishing pigs fed low CP diets supplemented with CAA.

\section{MATERIALS AND METHODS}

All experimental procedures and animal care were approved by the China Agricultural University Animal Care and Use Committee.

\section{Experimental design, animals, housing and diets}

Two experiments were conducted to determine the SID Lys requirement and the ideal SID Thr to Lys ratio for finishing barrows (Yorkshire $\times$ Landrace) fed low CP diets. In both experiments, pigs were placed in $3.0 \mathrm{~m} \times 4.0 \mathrm{~m}$ pens equipped with a single-sided five-hole feeder and two nipple drinkers. Feed and water were supplied ad libitum. Pigs were weighed after an overnight fast at the beginning and end of the experiment to determine weight gain. Feed disappearance was measured weekly to calculate feed intake.

Exp. 1 was carried out to estimate the requirement for SID Lys in finishing barrows fed low CP, AA supplemented diets. In Exp. 1, 120 barrows with an average body weight of $72.8 \pm 3.6 \mathrm{~kg}$ were allotted to one of six dietary treatments with five pens per treatment and four pigs per pen in a randomized complete block design for $35 \mathrm{~d}$. Diets consisted of corn, wheat bran, soybean meal and crystalline AAs (Table 1). A normal CP diet providing $15.3 \% \mathrm{CP}$ and $0.71 \%$ SID Lys, as well as five diets providing $12 \% \mathrm{CP}$ with SID Lys concentrations of $0.51,0.61,0.71,0.81$ and $0.91 \%$ were formulated. The reduction of nitrogen from the decreased essential AAs was offset by alanine to make the low CP diets isonitrogenous. SID ratios of the essential AAs to SID Lys were $110 \%$ of those recommended by the National Swine Nutrition Guide (NSNG, 2010).

In Exp. 2, 138 barrows $(72.5 \pm 4.4 \mathrm{~kg})$ were randomly allotted into five replicate pens of five or six barrows per pen for a $26 \mathrm{~d}$ trial. Five diets were formulated to contain

Table 1. Composition of experimental diets fed to determine the standardized ileal digestible (SID) lysine requirement and the optimum SID lysine (Lys) to threonine (Thr) ratio for finishing barrows (\%, as-fed basis)

\begin{tabular}{|c|c|c|c|c|c|c|c|}
\hline & \multirow{3}{*}{ Normal-CP ${ }^{1}$} & \multicolumn{5}{|c|}{ Exp.1 } & \multirow{3}{*}{$\begin{array}{l}\text { Basal diet for } \\
\text { Exp. } 2^{2}\end{array}$} \\
\hline & & \multicolumn{5}{|c|}{ SID lysine level in low- $\mathrm{CP}^{1}$ diets } & \\
\hline & & $0.51 \%$ & $0.61 \%$ & $0.71 \%$ & $0.81 \%$ & $0.91 \%$ & \\
\hline Corn $(7.8 \% \mathrm{CP})$ & 75.40 & 78.58 & 78.58 & 78.58 & 78.58 & 78.58 & 79.63 \\
\hline Wheat bran $(16.8 \% \mathrm{CP})$ & 1.50 & 12.00 & 12.00 & 12.00 & 12.00 & 12.00 & 13.50 \\
\hline Soybean meal $(43.5 \% \mathrm{CP})$ & 20.50 & 5.00 & 5.00 & 5.00 & 5.00 & 5.00 & 3.50 \\
\hline Corn starch & 0.00 & 0.33 & 0.27 & 0.18 & 0.09 & 0.00 & 0.00 \\
\hline Limestone & 0.90 & 1.00 & 1.00 & 1.00 & 1.00 & 1.00 & 1.00 \\
\hline Dicalcium phosphate & 0.70 & 0.70 & 0.70 & 0.70 & 0.70 & 0.70 & 0.70 \\
\hline Salt & 0.40 & 0.40 & 0.40 & 0.40 & 0.40 & 0.40 & 0.40 \\
\hline L-lysine $\cdot \mathrm{HCl}$ & 0.10 & 0.25 & 0.37 & 0.50 & 0.63 & 0.75 & 0.43 \\
\hline DL- methionine & 0.00 & 0.00 & 0.06 & 0.13 & 0.19 & 0.25 & 0.10 \\
\hline L-threonine & 0.00 & 0.05 & 0.12 & 0.19 & 0.26 & 0.33 & 0.06 \\
\hline L-tryptophan & 0.00 & 0.01 & 0.02 & 0.04 & 0.06 & 0.08 & 0.04 \\
\hline L-isoleucine & 0.00 & 0.00 & 0.03 & 0.09 & 0.14 & 0.20 & 0.08 \\
\hline L-valine & 0.00 & 0.00 & 0.01 & 0.07 & 0.14 & 0.21 & 0.06 \\
\hline L-alanine & 0.00 & 1.18 & 0.94 & 0.62 & 0.31 & 0.00 & 0.00 \\
\hline Vitamin and mineral premix ${ }^{3}$ & 0.50 & 0.50 & 0.50 & 0.50 & 0.50 & 0.50 & 0.50 \\
\hline
\end{tabular}

${ }^{1}$ Normal-CP and low-CP represent diets that were formulated to contain $15.3 \%$ CP with $0.71 \%$ SID lysine and $12 \%$ CP with SID lysine of $0.51,0.61$, $0.71,0.81$ and $0.91 \%$.

${ }^{2}$ Diets in Exp. 2 were formulated to contain $0.61 \%$ SID lysine and were created by replacing part of the corn of the basal diet with $0,0.04,0.09,0.10$ and $0.13 \%$ L-threonine.

${ }^{3}$ Supplied per kilogram of diet (as-fed basis): vitamin A, 7,200 IU; vitamin $\mathrm{D}_{3}, 1,400 \mathrm{IU}$; vitamin E, $20 \mathrm{IU}$; vitamin $\mathrm{K}_{3}$, $0.5 \mathrm{mg}$; thiamine,1.6 mg; pyridoxine, $2 \mathrm{mg}$; vitamin $\mathrm{B}_{12}, 24.0 \mu \mathrm{g}$; riboflavin, $4.0 \mathrm{mg}$; pantothenic acid, $12.0 \mathrm{mg}$; niacin, $24.0 \mathrm{mg}$; folic acid, $0.8 \mathrm{mg}$; choline chloride, $400 \mathrm{mg}$; Fe, $120 \mathrm{mg}$ (as ferrous sulfate); $\mathrm{Cu}, 75 \mathrm{mg}$ (as copper sulfate); $\mathrm{Zn}, 100 \mathrm{mg}$ (as zinc sulfate); Mn, $40 \mathrm{mg}$ (as manganese sulfate); I, $0.3 \mathrm{mg}$ (as calcium iodate); Se, $0.3 \mathrm{mg}$ (as sodium selenite); Beijing Resource Feed Company, Beijing, China. 
Table 2. Analyzed total and calculated standardized ileal digestible (SID) amino acid (AA) composition of diets (Exp.1, as-fed basis) ${ }^{1}$

\begin{tabular}{|c|c|c|c|c|c|c|}
\hline & \multirow{2}{*}{ Normal-CP ${ }^{2}$} & \multicolumn{5}{|c|}{ SID lysine level in low-CP diets ${ }^{2}$} \\
\hline & & $0.51 \%$ & $0.61 \%$ & $0.71 \%$ & $0.81 \%$ & $0.91 \%$ \\
\hline \multicolumn{7}{|c|}{ Analyzed values (\%) } \\
\hline Crude protein & 15.27 & 12.04 & 11.97 & 12.02 & 11.81 & 12.54 \\
\hline Arginine & 0.85 & 0.53 & 0.58 & 0.59 & 0.58 & 0.60 \\
\hline Histidine & 0.46 & 0.34 & 0.36 & 0.35 & 0.36 & 0.36 \\
\hline Isoleucine & 0.64 & 0.39 & 0.42 & 0.47 & 0.53 & 0.58 \\
\hline Leucine & 1.26 & 0.98 & 0.99 & 1.03 & 1.04 & 0.99 \\
\hline Lysine & 0.87 & 0.63 & 0.72 & 0.83 & 0.94 & 1.02 \\
\hline Methionine & 0.28 & 0.28 & 0.28 & 0.35 & 0.40 & 0.44 \\
\hline Threonine & 0.59 & 0.47 & 0.52 & 0.59 & 0.64 & 0.70 \\
\hline Tryptophan & 0.17 & 0.13 & 0.14 & 0.15 & 0.17 & 0.17 \\
\hline Valine & 0.86 & 0.63 & 0.68 & 0.73 & 0.80 & 0.87 \\
\hline \multicolumn{7}{|l|}{ SID AAs $(\%)^{3}$} \\
\hline Lysine & 0.71 & 0.51 & 0.61 & 0.71 & 0.81 & 0.91 \\
\hline Sulfur $\mathrm{AA}^{4}$ & 0.50 & 0.37 & 0.43 & 0.50 & 0.55 & 0.61 \\
\hline Threonine & 0.51 & 0.36 & 0.43 & 0.50 & 0.57 & 0.64 \\
\hline Tryptophan & 0.15 & 0.10 & 0.11 & 0.13 & 0.15 & 0.17 \\
\hline Isoleucine & 0.57 & 0.33 & 0.36 & 0.42 & 0.48 & 0.53 \\
\hline Valine & 0.65 & 0.44 & 0.45 & 0.51 & 0.58 & 0.65 \\
\hline
\end{tabular}

${ }^{1}$ Analyzed values for $\mathrm{CP}$ and AAs are shown and are based on a composite sample obtained weekly.

${ }^{2}$ Normal-CP and low-CP represent diets that were formulated to contain $15.3 \%$ CP with $0.71 \%$ SID lysine and $12 \%$ CP with SID lysine of $0.51,0.61$, $0.71,0.81$ and $0.91 \%$.

${ }^{3}$ Digestibility values for the diets were estimated by multiplying the analyzed AAs levels by the standardized ileal digestibility of the corresponding AA in those feedstuffs (AminoDat 3.0. 2005; Evonik Degussa GmbH, Hanau, Germany).

${ }^{4}$ Sulfur AA, methionine plus cystine.

SID Thr to Lys ratios of $0.56,0.61,0.67,0.72$, and 0.77 (Table 2). All diets were formulated to contain $0.61 \%$ SID Lys $(10.5 \% \mathrm{CP})$, which is slightly below the pig's requirement. The different SID Thr to Lys ratios were created by replacing part of the corn with crystalline Thr (Table 1). SID values for the complete diets were estimated by multiplying the analyzed AA levels in corn, soybean meal and wheat bran by the SID of the corresponding AA in those feedstuffs (AminoDat 3.0. 2005; Evonik Degussa $\mathrm{GmbH}$, Hanau, Germany). SID AA profiles for lysine, methionine+cystine, tryptophan, valine and isoleucine were formulated to meet the values recommended by NSNG (2010) for finishing barrows.

\section{Collection and sampling}

Representative feed samples were taken weekly. At the termination of the experiment, blood samples were taken from one pig per pen before the morning feeding via anterior vena cava puncture into $10-\mathrm{ml}$ heparin-free vacutainer tubes (Becton Dickinson Vacutainer Systems, Franklin Lakes, NJ, USA) to determine the concentrations of SUN and serum AA. Pigs whose weight was nearest the average for each pen were selected for bleeding. Blood samples were centrifuged at 1,200 $\times$ g (Heraeus Biofuge 22R Centrifuge, Hanau, Germany) for $15 \mathrm{~min}$ at room temperature and the serum was immediately stored at $-20^{\circ} \mathrm{C}$ for later analysis.

\section{Chemical analysis}

Crude protein was analyzed according to AOAC (2003) procedures. The AA contents in diets were analyzed by ionexchange chromatography using a Hitachi L-8800 Amino Acid Analyzer (Tokyo, Japan) after acid hydrolysis with 6 $\mathrm{N} \mathrm{HCl}$ (reflux for $23 \mathrm{~h}$ at $110^{\circ} \mathrm{C}$ ). The cystine and methionine contents in the diets were measured after performic oxidation before hydrolysis and the tryptophan content in diets was determined after alkaline hydrolysis at $120^{\circ} \mathrm{C}$ for $16 \mathrm{~h}$ (AOAC, 2003), separated by reverse-phase HPLC (Waters 2690, Milford, MA).

Frozen serum samples were first thawed at $4{ }^{\circ} \mathrm{C}$ and deproteinized by using $120 \mathrm{mg}$ of salicylsulfonic acid/ $/ \mathrm{ml}$ of serum. After sitting in an ice bath for $20 \mathrm{~min}$, the reaction system was adjusted for $\mathrm{pH}$ by adding a lithium hydroxide solution $(2 \mathrm{~mol} / \mathrm{L})$ and then centrifuged in an ultracentrifuge with a fixed angle rotor (Beckman Optima L80-XP, Beckman Coulter Inc., Fullerton, CA, USA) at 11,000 $\times$ g for $30 \mathrm{~min}$ at $4^{\circ} \mathrm{C}$. The supernatant was collected and then passed through a filter $(0.1 \mu \mathrm{m})$. Serum AA concentrations of barrows were determined by ion-exchange chromatography with physiological fluid analysis conditions (S-433D Amino Acid Analyzer, Sykam, Germany). SUN concentrations were determined with a 
Table 3. Analyzed total and calculated standardized ileal digestible (SID) amino acid (AA) composition of diets (Exp. 2, as-fed basis) ${ }^{1}$

\begin{tabular}{|c|c|c|c|c|c|}
\hline & \multicolumn{5}{|c|}{ SID threonine to lysine ratio } \\
\hline & 0.56 & 0.61 & 0.67 & 0.72 & 0.77 \\
\hline \multicolumn{6}{|c|}{ Analyzed value (\%) } \\
\hline Crude protein & 11.03 & 10.10 & 10.51 & 10.51 & 10.38 \\
\hline Arginine & 0.49 & 0.47 & 0.50 & 0.50 & 0.54 \\
\hline Histidine & 0.31 & 0.31 & 0.31 & 0.30 & 0.33 \\
\hline Isoleucine & 0.40 & 0.40 & 0.42 & 0.41 & 0.42 \\
\hline Leucine & 0.94 & 0.93 & 0.98 & 0.96 & 0.98 \\
\hline Lysine & 0.67 & 0.67 & 0.67 & 0.67 & 0.68 \\
\hline Methionine & 0.23 & 0.26 & 0.25 & 0.24 & 0.27 \\
\hline Threonine & 0.42 & 0.45 & 0.49 & 0.51 & 0.56 \\
\hline Tryptophan & 0.12 & 0.13 & 0.12 & 0.13 & 0.13 \\
\hline Valine & 0.67 & 0.64 & 0.68 & 0.67 & 0.67 \\
\hline \multicolumn{6}{|l|}{ SID AAs $(\%)^{2}$} \\
\hline Lysine & 0.61 & 0.61 & 0.61 & 0.61 & 0.61 \\
\hline Sulfur $\mathrm{AA}^{3}$ & 0.45 & 0.45 & 0.45 & 0.45 & 0.45 \\
\hline Threonine & 0.34 & 0.37 & 0.41 & 0.44 & 0.47 \\
\hline Tryptophan & 0.12 & 0.12 & 0.12 & 0.12 & 0.12 \\
\hline Isoleucine & 0.35 & 0.35 & 0.35 & 0.35 & 0.35 \\
\hline Valine & 0.47 & 0.47 & 0.47 & 0.47 & 0.47 \\
\hline
\end{tabular}

${ }^{1}$ Analyzed values for CP and AAs are shown and are based on a composite sample obtained weekly.

${ }^{2}$ Digestibility values for the diets were estimated by multiplying the analyzed AAs levels by the standardized ileal digestibility of the corresponding AA in those feedstuffs (AminoDat 3.0. 2005; Evonik Degussa GmbH, Hanau, Germany).

${ }^{3}$ Sulfur AA, methionine plus cystine.

blood urea nitrogen color test kit (Nanjing Jiancheng Bioenineering Insitute, Nanjing, China).

\section{Statistical analysis}

Data for each response criterion were analyzed by PROC GLM of SAS (SAS Institute, Cary, NC, USA) with dietary SID Lys (Exp. 1) or SID Thr to Lys ratio (Exp. 2) and replicate included in the model. The pen was considered the experimental unit for all variables. The LSMEANS procedure of SAS was used to calculate mean values. Linear and quadratic comparisons were used to evaluate the effects of increasing SID Lys (Exp. 1) or SID Thr to Lys ratio (Exp. 2). Alpha levels of $p \leq 0.05$ and $p<0.10$ were the criterion for statistical significance and tendencies. The response to an increasing SID Thr supply was analyzed by linear broken-line analysis (Robbins et al., 2006), along with the asymptote of the quadratically fitted line using SAS.

\section{RESULTS}

In Exp. 1, the highest weight gain and the lowest FCR and SUN concentrations were found in barrows fed the 0.71 , 0.81 and $0.81 \%$ SID Lys diets, respectively (Table 4). Increasing the SID Lys content of the diet resulted in an increase in weight gain (linear effect $\mathrm{p}=0.04$ and quadratic effect $\mathrm{p}=0.08$ ) and improvement in FCR (linear effect $\mathrm{p}=$ 0.02 and quadratic effect $\mathrm{p}=0.02$ )

Using a linear broken-line model, the estimated SID Lys requirement of finishing barrows was $0.71 \%$ for both

Table 4. Effect of standardized ileal digestible (SID) lysine and crude protein (CP) on performance and serum urea nitrogen of 72 to 104 kg barrows (Exp.1) ${ }^{1}$

\begin{tabular}{|c|c|c|c|c|c|c|c|c|c|}
\hline & \multirow{2}{*}{ Normal-CP ${ }^{2}$} & \multicolumn{5}{|c|}{ SID lysine in low- $\mathrm{CP}^{2}$} & \multirow{2}{*}{ SEM } & \multicolumn{2}{|c|}{ p-value } \\
\hline & & $0.51 \%$ & $0.61 \%$ & $0.71 \%$ & $0.81 \%$ & $0.91 \%$ & & Linear & Quadratic \\
\hline Weight gain $(\mathrm{kg} / \mathrm{d})$ & 0.88 & 0.82 & 0.85 & 0.92 & 0.91 & 0.89 & 0.04 & 0.04 & 0.08 \\
\hline Feed intake (kg/d) & 2.70 & 2.55 & 2.55 & 2.68 & 2.64 & 2.63 & 0.12 & 0.43 & 0.72 \\
\hline Feed conversion ratio & 3.05 & 3.12 & 3.02 & 2.91 & 2.90 & 2.96 & 0.07 & 0.02 & 0.02 \\
\hline Daily SID lysine intake (g) & 19.2 & 13.0 & 15.6 & 19.0 & 21.4 & 23.9 & 0.87 & $<0.01$ & $<0.01$ \\
\hline Serum urea nitrogen $(\mathrm{mg} / \mathrm{dl})$ & 21.6 & 16.0 & 15.6 & 15.1 & 14.0 & 15.3 & 0.98 & 0.21 & 0.31 \\
\hline
\end{tabular}

${ }^{1}$ A total of 120 barrows representing the mean of five pens per treatment and four pigs per pen for a $35 \mathrm{~d}$ trial.

${ }^{2}$ Normal-CP and low-CP represent diets that were formulated to contain $15.3 \%$ CP with $0.71 \%$ SID lysine and $12 \%$ CP with SID lysine of $0.51,0.61$, $0.71,0.81$ and $0.91 \%$. 


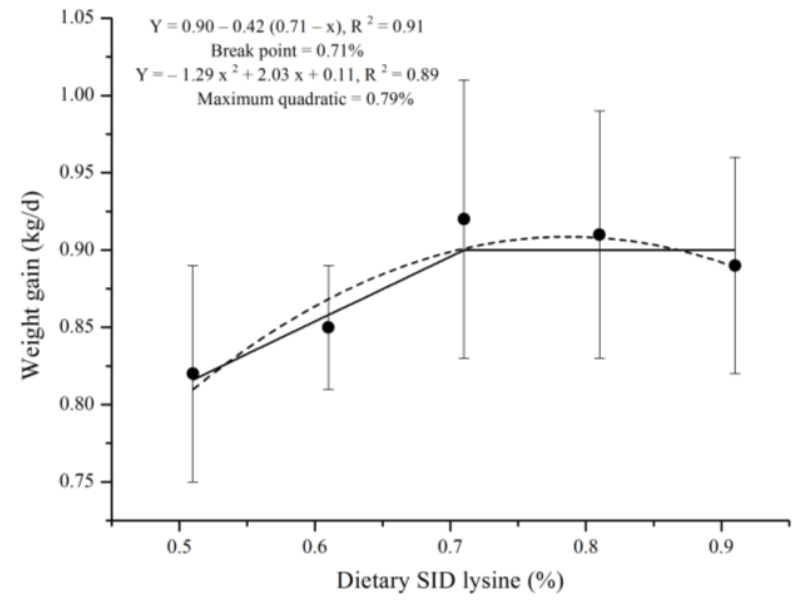

Figure 1. Fitted broken line (-) and quadratic (---) plot of weight gain plotted against standardized ileal digestible lysine (Exp. 1).

weight gain and FCR (Figures 1 and 2). When a quadratic analysis was conducted, the estimated SID Lys requirements were 0.79 and $0.78 \%$ to maximize weight gain and minimize FCR, respectively (Figures 1 and 2).

In Exp. 2, the highest weight gain and the lowest FCR and SUN concentrations were found in barrows fed SID Thr to Lys ratios of $0.67,0.72$ and 0.67 , respectively (Table 5). Improvements in weight gain (quadratic effect $p=0.03$ ), feed intake (quadratic effect $p=0.02$ ) and FCR (linear effect $\mathrm{p}=0.02$ and quadratic effect $\mathrm{p}=0.06$ ) were observed with increasing SID Thr to Lys ratios. SUN concentrations were also significantly affected by increasing SID Thr to Lys ratios (linear effect $\mathrm{p}=0.03$ and quadratic effect $\mathrm{p}=$ 0.02). Supplementation with $\mathrm{Thr}$ increased the serum concentrations of Thr (linear effect $\mathrm{p}=0.04$ and quadratic effect $p=0.07$ ) and glutamic acid (linear effect $p=0.02$ and quadratic effect $\mathrm{p}=0.07$; Table 6).

Using a linear broken-line model, the optimal SID Thr to Lys ratio to maximize weight gain (Figure 3), and optimize FCR (Figure 4) and SUN (Figure 5) were 0.67, 0.71 and 0.64 . Using the quadratic model, the optimal SID Thr to Lys ratio to maximize weight gain (Figure 3), and optimize FCR (Figure 4) and SUN (Figure 5) were 0.68, 0.78 and 0.70 .

Table 5. Effects of standardized ileal digestible (SID) threonine to lysine ratio on performance and serum urea nitrogen of 72 to $95 \mathrm{~kg}$ barrows (Exp. 2) ${ }^{1}$

\begin{tabular}{|c|c|c|c|c|c|c|c|c|}
\hline & \multicolumn{5}{|c|}{ SID threonine to lysine ratio } & \multirow{2}{*}{ SEM } & \multicolumn{2}{|c|}{$\mathrm{p}$-value } \\
\hline & 0.56 & 0.61 & 0.67 & 0.72 & 0.77 & & Linear & Quadratic \\
\hline Weight gain $(\mathrm{kg} / \mathrm{d})$ & 0.82 & 0.85 & 0.91 & 0.90 & 0.85 & 0.03 & 0.14 & 0.03 \\
\hline Feed intake $(\mathrm{kg} / \mathrm{d})$ & 2.53 & 2.56 & 2.68 & 2.61 & 2.48 & 0.05 & 0.87 & 0.02 \\
\hline Feed conversion ratio & 3.11 & 3.04 & 2.96 & 2.89 & 2.91 & 0.08 & 0.02 & 0.06 \\
\hline Daily SID threonine intake (g) & 8.8 & 9.7 & 11.2 & 11.8 & 11.9 & 0.21 & $<0.01$ & $<0.01$ \\
\hline Serum urea nitrogen $(\mathrm{mg} / \mathrm{dl})$ & 12.2 & 10.5 & 8.9 & 9.4 & 9.7 & 0.89 & 0.03 & 0.02 \\
\hline
\end{tabular}

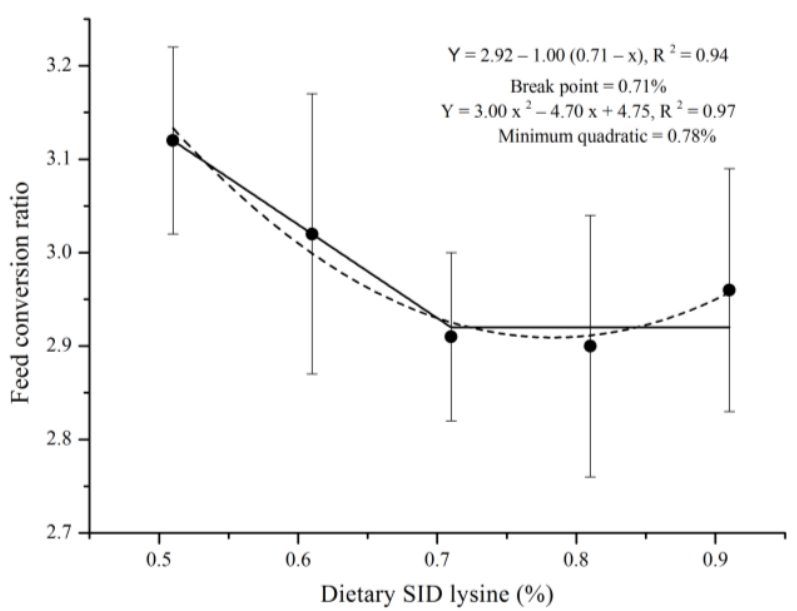

Figure 2. Fitted broken line (-) and quadratic (---) plot of feed conversion ratio plotted against standardized ileal digestible lysine (Exp. 1).

\section{DISCUSSION}

Protein sources are among the most expensive ingredients in swine diets and therefore nutritionists attempt to formulate diets that will maximize the efficiency of growth and minimize the excretion of nitrogenous waste (Gabert et al., 2001). Two concepts widely utilized for the formulation of "efficient and environmentally friendly" diets are the ideal protein concept and the formulation of diets based on digestible or available nutrients (Chiba, 2001).

The most widely utilized estimates of the requirements of pigs for SID AA are those of the British Society of Animal Science (BSAS, 2003), Evonik Industries (Rademacher et al., 2009), the NSNG (2010) and NRC (2012). The NSNG (2010) estimates the SID Lys requirement of 81 to $102 \mathrm{~kg}$ pigs to be $0.72 \%$ for high lean gain lines of barrows, $0.62 \%$ for medium lean gain lines of barrows. Evonik Industries (Rademacher et al., 2009) estimates the Lys requirement of 70 to $105 \mathrm{~kg}$ pigs to be $0.71 \%$ SID Lys, NRC (2012) estimates the Lys requirement of 75 to $105 \mathrm{~kg}$ pigs to be $0.73 \%$ SID Lys while BSAS (2003) estimates the SID Lys requirement of 60 to $90 \mathrm{~kg}$ pigs to be $0.51 \%$ for slow growing pigs, $0.71 \%$ for

${ }^{1} \mathrm{~A}$ total of 138 barrows representing the mean of five pens per treatment and five or six pigs per pen for a $26 \mathrm{~d}$ trial. 
Table 6. Effect of the standardized ileal digestible (SID) threonine to lysine ratio in the diet on the serum amino acid (AA) concentrations in barrows $(\mathrm{nmol} / \mathrm{mL})^{1}$

\begin{tabular}{|c|c|c|c|c|c|c|c|c|}
\hline & \multicolumn{5}{|c|}{ SID threonine to lysine ratio } & \multirow{2}{*}{ SEM } & \multicolumn{2}{|c|}{$\mathrm{p}$-value } \\
\hline & 0.56 & 0.61 & 0.67 & 0.72 & 0.77 & & Linear & Quadratic \\
\hline \multicolumn{9}{|c|}{ Serum indispensable AAs } \\
\hline Arginine & 327.8 & 343.6 & 348.0 & 367.6 & 376.0 & 42.61 & 0.29 & 0.32 \\
\hline Histidine & 109.0 & 120.6 & 124.9 & 111.0 & 126.1 & 18.05 & 0.85 & 0.80 \\
\hline Isoleucine & 128.4 & 149.3 & 139.7 & 141.3 & 140.2 & 16.95 & 0.67 & 0.64 \\
\hline Leucine & 286.8 & 332.9 & 305.4 & 342.5 & 322.9 & 36.40 & 0.34 & 0.56 \\
\hline Lysine & 524.1 & 545.7 & 582.0 & 508.4 & 540.2 & 82.53 & 0.67 & 0.91 \\
\hline Methionine & 68.1 & 80.2 & 75.3 & 78.5 & 88.0 & 12.19 & 0.84 & 0.86 \\
\hline Phenylalanine & 107.1 & 125.1 & 129.0 & 119.8 & 120.9 & 21.43 & 0.62 & 0.66 \\
\hline Threonine & 122.1 & 178.9 & 194.6 & 184.6 & 240.9 & 24.51 & 0.04 & 0.07 \\
\hline Tryptophan & 85.2 & 72.7 & 85.0 & 85.6 & 80.1 & 12.73 & 0.39 & 0.68 \\
\hline Valine & 350.4 & 372.7 & 369.6 & 350.0 & 356.4 & 45.09 & 0.92 & 0.85 \\
\hline \multicolumn{9}{|c|}{ Serum dispensable AAs } \\
\hline Alanine & 679.2 & 813.8 & 728.1 & 834.1 & 804.6 & 118.39 & 0.31 & 0.59 \\
\hline Aspartic acid & 21.0 & 19.3 & 15.6 & 16.7 & 21.9 & 3.91 & 0.27 & 0.28 \\
\hline Cystine & 12.5 & 10.8 & 12.3 & 15.3 & 21.4 & 2.34 & 0.17 & 0.11 \\
\hline Glutamic acid & 216.5 & 306.5 & 211.5 & 287.8 & 297.5 & 61.76 & 0.02 & 0.07 \\
\hline Glycine & 1714.4 & 1743.8 & 1722.4 & 1844.4 & 1764.6 & 214.37 & 0.84 & 0.97 \\
\hline Proline & 372.7 & 434.1 & 389.6 & 374.8 & 480.8 & 68.06 & 0.75 & 0.95 \\
\hline Serine & 199.5 & 209.0 & 191.4 & 186.4 & 225.1 & 26.05 & 0.82 & 0.91 \\
\hline Tyrosine & 123.4 & 130.8 & 134.0 & 122.9 & 137.5 & 16.40 & 0.76 & 0.94 \\
\hline
\end{tabular}

${ }^{1}$ Blood samples were collected from five pigs per treatment (one pig per pen) at the end of the experiment.

intermediate pigs and $0.89 \%$ for fast growing pigs. However, it is important to realize that these estimates are typically determined using a prediction model and are not based on any empirical experiments (Hans Stein, University of Illinois; Personal Communication). It is important that the estimates of prediction models be validated with actual experimental data.

Exp. 1 was carried out to estimate the requirement for SID Lys in finishing barrows fed low CP, AA supplemented

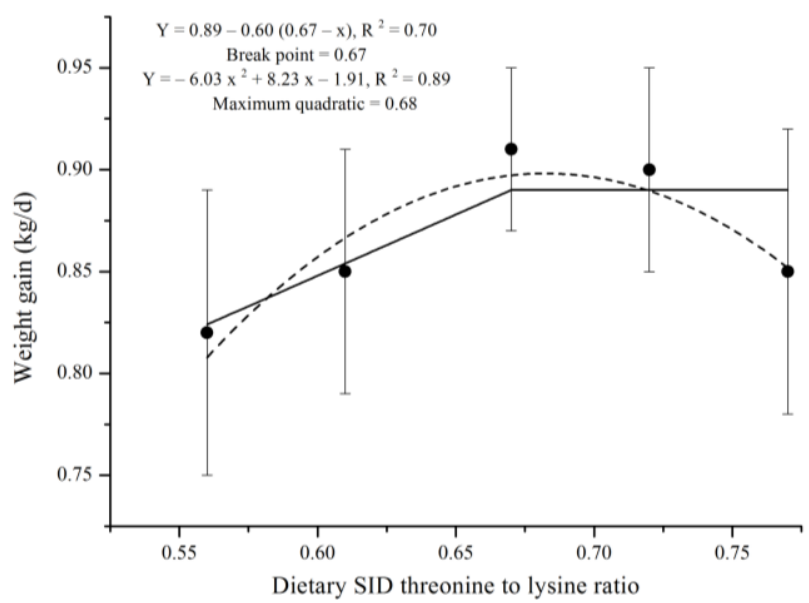

Figure 3. Fitted broken line (-) and quadratic (---) plot of weight gain plotted against standardized ileal digestible threonine to lysine ratio (Exp. 2). diets. Averaging the values from the broken-line and quadratic analysis, the dietary SID Lys requirement for both maximum weight gain and minimum FCR was $0.75 \%$, which is in good agreement with previously published values. The results of Exp. 1 clearly demonstrate that pigs fed low CP diets supplemented with CAA can achieve the same performance as pigs fed normal CP levels. An advantage of feeding low $\mathrm{CP}$ diets supplemented with CAA is that nitrogen excretion and feed costs may be reduced

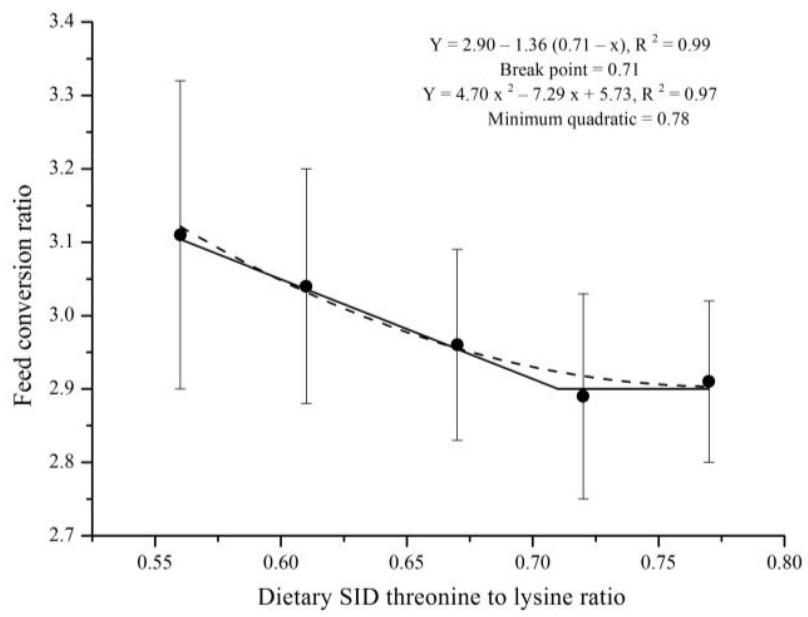

Figure 4. Fitted broken line (-) and quadratic (---) plot of feed conversion ratio plotted against standardized ileal digestible threonine to lysine ratio (Exp. 2). 


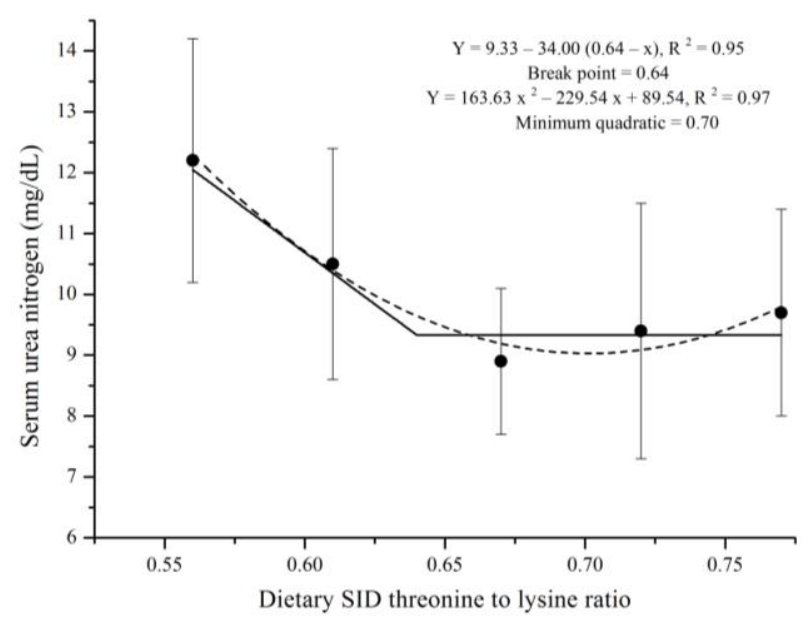

Figure 5. Fitted broken line (-) and quadratic (---) plot of serum urea nitrogen plotted against standardized ileal digestible threonine to lysine ratio (Exp. 2).

(Kerr et al., 1995). Whether or not any cost savings are actually achieved will depend on the relative price of CAA compared with the protein ingredients they replace.

Another important means of achieving maximal efficiency of swine growth is to design AA patterns that contain neither deficiencies nor excesses of AA. A protein that contains a perfect balance of AA has been described as an ideal protein (Fuller and Wang, 1990; Baker et al., 1993; Cole and Van Lunen, 1994). The concept of the ideal protein allows for a rapid estimation of requirements for essential AA once the requirement for one AA, typically Lys, has been established. The concept of an ideal protein has largely been utilized to determine the optimum ratios for total AA in the diet and few attempts have been made to establish the optimum ratios of SID AA.

Exp. 2 was conducted to determine the ideal ratio of SID Thr to Lys for finishing barrows. For establishing the optimal ratio between two specific AAs, it is important that pigs are fed diets limiting in Lys (Boisen, 2003). To secondarily limit Lys, a level of $0.61 \%$ SID Lys was formulated in titration diet, which is about $20 \%$ lower than the present study for finishing pigs. Averaging the values from the broken-line and quadratic analysis, an optimum SID Thr to Lys ratio for finishing barrows is 0.68 to maximize weight gain, 0.75 to optimize FCR and 0.67 to minimize SUN.

Estimates of the required ratio of Thr to Lys in ideal protein vary from 0.60 to 0.75 (Fuller and Wang, 1990; Baker et al., 1993; Cole and van Lunen, 1994; Boisen et al., 2003). Based largely on these estimates of ideal protein, both BSAS (2003) and NSNG (2010) recommend an SID Thr to Lys ratio of 0.65 , while Evonik Industries (Rademacher et al., 2009) recommends an SID Thr to Lys ratio of 0.70 and NRC (2012) recommends an SID Thr to
Lys ratio of 0.63 for finishing pigs.

To date, very few empirical studies have been conducted to determine the optimum SID Thr to Lys ratio for finishing pigs and we are unaware of any previous experiments in which the optimum SID Thr to Lys ratio has been determined for finishing pigs fed low CP diets. Pedersen et al. (2003) demonstrated that the optimum SID Thr to Lys ratio for 60 to $110 \mathrm{~kg}$ pigs was found to be 0.62 to 0.64. Plitzner et al. (2007) also found a similar optimal SID Thr to Lys of 0.62 to 0.64 with 67 to $113 \mathrm{~kg}$ pigs and also suggested that the ratio rises as pigs move towards the late finishing stage. Therefore, the results of the present study are within the range of previously reported values for the optimum SID Thr to Lys ratio for finishing pigs, the results obtained tend to be on the high side of the range.

A potential explanation for this finding may relate to the CP level of the diet used. Support for this concept can be obtained from the work of Zhai and Adeola (2011) who reported that the CP level in corn soybean meal diets affected the SID of Thr, leucine and phenylalanine. Moreover, Li et al. (1999) found that relative to Lys of Thr required to maximize immune response is greater than that required for maximum weight gain and increasing dietary Thr levels increased plasma antibody concentration. Compared with most of the experiments conducted in a research setting, the data of current experiment were obtained under commercial conditions where pigs were confronted with many challenges. Therefore, further research should be conducted to determine whether or not the optimum SID Thr to Lys ratio is affected by dietary CP level.

In the present study, the optimum SID Thr to Lys ratio was dependent on whether weight gain, FCR or SUN was used as the response criteria. This finding agrees with the studies of Pedersen et al. (2003) who also reported that the optimum SID Thr to Lys ratio was dependent on the response criteria used. The reduction in plasma urea presumably reflected more efficient nitrogen utilization and less urea synthesis when the quality and quantity of AA approached the requirement of pigs (Verstegen and Jongbloed, 2003). Whang and Easter (2000) demonstrated that blood urea nitrogen values are highly correlated with lean gain and feed efficiency in pigs. However, the choice as to which ratio to use will ultimately depend upon producer objectives but as there is little economic incentive to minimizing SUN, it is likely that producers would choose between ratios generated using weight gain and FCR.

In a dose-response experiment, choice of a statistical model is critical to interpreting nutritional requirements (Pesti et al., 2009). Quadratic models are easy to fit to data (only three levels are needed) and can accurately model the increase and decrease in performance, which shape 
represents the response to graded concentrations of a nutrient up to the point when it becomes "safe" or "toxic". Broken line models fit the ascending and plateau portions well, which as concentrations of a nutrient are increased in the diet, there is a change in response up to some point, which is the requirement (Pesti et al., 2009). Linear brokenline analysis is preferred by some studies because the requirement is taken to be the minimum intake needed for maximum retention (Fuller and Garthwaite, 1993). However, a linear broken-line response is predicted for an average pig and the requirement can be considered as the requirement for a theoretical average pig (Baker, 1986). For the purpose of safety and comparison, both models were chosen as the approach to determine the requirement of AA in the present experiment.

It is generally believed that a systemic blood AAs profile reflects tissue utilization and metabolism (Wiltafsky et al., 2009). In Exp. 2, an increased ratio of Thr to Lys in diets resulted in a linearly increase in serum $\mathrm{Thr}$ concentration $(p=0.04)$, which agrees with the results of Kendall et al. (2007), where serum concentration of the test AA increased linearly with the increased dietary test AA. Furthermore, changes in serum concentrations of test AA were used by Wiltafsky et al. (2009) to estimate the optimal AA needs of pigs, which was based on the hypothesis that an increasing dietary supply of an AA had little effect on serum concentrations until the requirement is met, but will linearly increase serum concentrations when the diet contains adequate or excess amounts. However, a sharp increase of serum AA concentration was not found in the present study, presumably caused by lower levels of dietary Thr and the different time of blood collection used by Wiltafsky et al. (2009).

\section{CONCLUSION}

Averaging the values from broken-line and quadratic analysis, we concluded that the dietary SID Lys requirement for both maximum weight gain and minimum FCR was $0.75 \%$, and an optimum SID Thr to Lys ratio was 0.68 to maximize weight gain, 0.75 to optimize FCR and 0.67 to minimize SUN for finishing barrows, these ratios were higher than current recommendation of 0.63 for 75 to 100 $\mathrm{kg}$ finishing pigs (NRC, 2012).

\section{ACKNOWLEDGEMENTS}

This work was financially supported by the Modern Agro-Industry Technology Research System of Beijing and National Key Basic Research Program of China (No. 2012CB124702). The authors thank the Dacheng group, ChangChun, China and Health and Nutrition, Evonik Degussa GmbH, Germany, for providing supplemental AAs.
We also thank P. A. Thacker for comments on the manuscript.

\section{REFERENCES}

AOAC. 2003. Official Methods of Analysis. 17th edn. Association of Official Analytical Chemists, Arilington, VA.

Baker, D. H. 1986. Problems and pitfalls in animal experiments designed to establish dietary requirements for essential nutrients. J. Nutr. 116:2339-2349.

Baker, D. H., J. D. Hahn, T. K. Chung, and Y. Han. 1993. Nutrition and growth: The concept and application of an ideal protein for swine growth. In: Growth of the Pig (Ed. G. R. Hollis). CAB International, Wallingford. pp. 133-139.

Boisen, S. 2003. Ideal dietary amino acid profiles for pigs. In: Amino Acids in Animal Nutrition, 2nd Ed. (Ed. J. P. F. D'Mello).. CABI Publishing, Edinburgh. pp. 157-168.

BSAS. 2003. Nutrient requirement standards for pigs. British Society of Animal Science, Penicuik, Midlothian, UK.

Chen, H. Y., X. W. Yi, G. J. Zhang, N. Lu, L. C. Chu, P. A. Thacker, and S. Y. Qiao. 2011. Studies on reducing nitrogen excretion: 1. Net energy requirements of finishing pigs maximizing performance and carcass quality fed low crude protein diets supplemented with crystalline amino acids. J. Anim. Sci. Biotech. 2:84-93.

Chiba, L. I. 2001. Protein supplements. In: Swine Nutrition, 2nd Ed. (Ed. A. J. Lewis and L. L. Southern). CRC Press, Boca Raton, Florida, USA. pp. 803-837.

Cole, D. J. A., and T. A. Van Lunen. 1994. Ideal amino acid patterns. In: Amino Acids in Farm Animal Nutrition (Ed. J. P. F. D’Mello). CAB International, Wallingford. pp. 99-112.

Deng, D., R. L. Huang, T. J. Li, G. Y. Wu, M. Y. Xie, Z. R. Tang, P. Kang, Y. M. Zhang, M. Z. Fan, X. F. Kong, Z. Ruan, H. Xiong, Z. Y. Deng, and Y. L. Yin. 2007a. Nitrogen balance in barrows fed low-protein diets supplemented with essential amino acids. Livest. Sci. 109:220-223.

Deng, D., A. K. Li, W. Y. Chu, R. L. Huang, T. J. Li, X. F. Kong, Z. J. Liu, G. Y. Wu, Y. M. Zhang, and Y. L. Yin. 2007b. Growth performance and metabolic responses in barrows fed lowprotein diets supplemented with essential amino acids. Livest. Sci. 109:224-227.

Ettle, T., D. A. Roth-Maier, J. Bartelt, and F. X. Roth. 2004. Requirement of true ileal digestible threonine of growing and finishing pigs. J. Anim. Physiol. Amin. Nutr. 88:211-222.

Evonik Degussa. 2005. AminoDat 3.0., platinum version. Evonik Degussa GmbH, Hanau-Wolfgang, Germany.

Fuller, M. F., I. Mennie, and R. M. J. Crofts. 1979. The optimal amino acid supplementation of barley for the growing pig 2 . Optimal additions of lysine and threonine for growth. Br. J. Nutr. 41:333-340.

Fuller, M. F., and T. C. Wang. 1990. Digestible ideal protein: A measure of dietary protein value. Pig News Info. 11:353-357.

Fuller, M. F., and P. Garthwaite. 1993. The form of response of body protein accretion to dietary amino acid supply. J. Nutr. 123:957-963.

Gabert, V. M., H. Jorgensen, and C. M. Nyachoti. 2001. Bioavailability of amino acids in feedstuffs for swine. In: Swine Nutrition, 2nd Ed. (Ed. A. J. Lewis and L. L. Southern). CRC Press, New York, pp. 151-186. 
Grosbach, D. A., A. J. Lewis, and J. E. R. Peo. 1985. An evaluation of threonine and isoleucine as the third and fourth limiting amino acids in corn for growing swine. J. Anim. Sci. 60:487-494.

Hansen, J. A., D. A. Knabe, and K. G. Burgoon. 1993. Amino acid supplementation of low-protein, sorghum-soybean meal diets for 20- to 50-kg swine. J. Anim. Sci. 71:442-451.

Kendall, D. C., A. M. Gaines, B. J. Kerr, and G. L. Allee. 2007. True ileal digestible tryptophan to lysine ratios in ninety- to one hundred twenty-five-kilogram barrows. J. Anim. Sci. 85:3004-3012.

Kerr, B. J., F. K. Mckeith, and R. A. Easter. 1995. Effects on performance and carcass characteristics of nursery to finisher pigs fed reduced crude protein, amino acid-supplemented diets. J. Anim. Sci. 73:433-440.

Kerr, B. J., L. L. Southern, T. D. Bidner, K. G. Friesen, and R. A. Easter. 2003. Influence of dietary protein level, amino acid supplementation, and dietary energy levels on growingfinishing pig performance and carcass composition. J. Anim. Sci. 81:3075-3087.

Kim, S. W., R. D. Mateo, Y. L. Yin, and G. Y. Wu. 2007. Functional amino acids and fatty acids for enhancing production performance of sows and piglets. Asian-Aust. J. Anim. Sci. 20:295-306.

Li, D. F., C. T. Xiao, S. Y. Qiao, J. H. Zhang, E. W. Johnson, and P. A. Thacker. 1999. Effects of dietary threonine on performance, plasma parameters and immune function of growing pigs. Anim. Feed Sci. Technol. 78:179-188.

Li, P., Y. L. Yin, D. F. Li, S. W. Kim, and G. Y. Wu. 2007. Amino acids and immune function. Br. J. Nutr. 98:237-252.

National Swine Nutrition Guide. 2010. National swine nutrition guide tables on nutrient recommendations, ingredient composition, and use rates. U.S. Pork Center of Excellence, USA.

National Research Council. 2012. Nutrient requirement of swine. 11th revised Ed. National Academy Press, Washington, DC, USA.

Pedersen, C., J. E. Lindberg, and S. Boisen. 2003. Determination of the optimal dietary threonine : lysine ratio for finishing pigs using three different methods. Livest. Prod. Sci. 82:233-243.
Pesti, G. M., D. Vedenov, J. A. Cason, and L. Billard. 2009. A comparison of methods to estimate nutritional requirements from experimental data. Br. Poult. Sci. 50:16-32.

Plitzner, C., T. Ettle, S. Handl, P. Schmidt, and W. Windisch. 2007. Effects of different dietary threonine levels on growth and slaughter performance in finishing pigs. Czech J. Anim. Sci. 52:447-455.

Rademacher, M., W. C. Sauer, and A. J. M. Jansman. 2009. Standardized Ileal Digestibility of Amino Acids in Pigs. Evonik Industries, Hanau-Wolfgang, Germany.

Robbins, K. R., A. M. Saxton, and L. L. Southern. 2006. Estimation of nutrient requirements using broken-line regression analysis. J. Anim. Sci. 84 (Suppl):E155- E165.

Saldana, C. I., D. A. Knabe, K. Q. Owen, K. G. Burgoon, and E. J. Gregg. 1994. Digestible threonine requirements of starter and finisher pigs. J. Anim. Sci. 72:144-150.

Sauer, W. C., and K. de Lange. 1992. Novel methods for determining protein and amino acid digestibilities in feedstuffs. In: Modern Methods in Protein Nutrition and Metabolism (Ed. S. Nissen). Academic Press Inc., San Diego, CA. pp. 87-120.

Schutte, J. B., J. deJong, W. Smink, and F. Koch. 1997. Threonine requirement of growing pigs (50 to $95 \mathrm{~kg}$ ) in relation to diet composition. Anim. Sci. 64:155-161.

Verstegen, M. W. A., and A. W. Jongbloed. 2003. Crystalline amino acids and nitrogen emission. In: Amino Acids in Animal Nutrition, 2nd Ed. (Ed. J. P. F. D'Mello). CABI Publishing, Edinburgh. pp. 449-458

Wang, X., S. Y. Qiao, Y. L. Yin, L. G. Yu, Z. Y. Wang, and G. Y. Wu. 2007. A deficiency or excess of dietary threonine reduces protein synthesis in jejunum and skeletal muscle of young pigs. J. Nutr. 137:1442-1446.

Whang, K. Y., and R. A. Easter. 2000. Blood urea nitrogen as an index of feed efficiency and lean growth potential in growingfinishing swine. Asian-Aus. J. Anim. Sci. 13:811-816.

Wiltafsky, M. K., B. Schmidtlein, and F. X. Roth. 2009. Estimates of the optimum dietary ratio of standardized ileal digestible valine to lysine for eight to twenty-five kilograms of body weight pigs. J. Anim. Sci. 87:2544-2553.

Zhai, H., and L. Adeola. 2011. Apparent and standardized ileal digestibilities of amino acids for pigs fed corn-soybean mealbased diets at varying crude protein levels. J. Anim. Sci. 89:3626-3633. 